\title{
Origins of Eukaryotic Sexual Reproduction
}

\author{
Ursula Goodenough ${ }^{1}$ and Joseph Heitman ${ }^{2}$ \\ ${ }^{1}$ Department of Biology, Washington University, St. Louis, Missouri 63130 \\ ${ }^{2}$ Department of Molecular Genetics and Microbiology, Duke University Medical Center, Durham, \\ North Carolina 27710 \\ Correspondence: ursula@biology2.wustl.edu; heitm001@duke.edu
}

\begin{abstract}
Sexual reproduction is a nearly universal feature of eukaryotic organisms. Given its ubiquity and shared core features, sex is thought to have arisen once in the last common ancestor to all eukaryotes. Using the perspectives of molecular genetics and cell biology, we consider documented and hypothetical scenarios for the instantiation and evolution of meiosis, fertilization, sex determination, uniparental inheritance of organelle genomes, and speciation.
\end{abstract}

$T^{\mathrm{h}}$ he transition from prokaryote to protoeukaryote to the last eukaryotic common ancestor (LECA) entailed conservation, modification, and reconfiguration of preexisting genetic circuits via mutation, horizontal gene transfer (HGT), endosymbiosis, and selection, as detailed in previous articles of this collection. During the course of this evolutionary trajectory, the LECA became sexual, reassorting and recombining chromosomes in a process that entails regulated fusions of haploid gametes and diploid $\rightarrow$ haploid reductions via meiosis. That the LECA was sexual is no longer a matter of speculation/ debate as evidence of sex, and of genes exclusively involved in meiosis, has been found in all of the major eukaryotic radiations (Brawley and Johnson 1992; Ramesh et al. 2005; Kobiyama et al. 2007; Malik et al. 2008; Phadke and Zufall 2009; Fritz-Laylin et al. 2010; Lahr et al. 2011; Peacock et al. 2011; Vanstechelman et al. 2013).

We propose that the transition to a sexual LECA entailed four innovations: (1) alterna- tion of ploidy via cell-cell fusion and meiosis; (2) mating-type regulation of cell-cell fusion via differentiation of complementary haploid gametes (isogametic and then anisogametic), a prelude to species-isolation mechanisms; (3) mating-type-regulated coupling of the diploid/meiotic state to the formation of adaptive diploid resting spores; and (4) matingtype-regulated transmission of organelle genomes. Our working assumption is that the protoeukaryote $\rightarrow$ LECA era featured numerous sexual experiments, most of which failed but some of which were incorporated, integrated, and modified. Therefore, this list is not intended to suggest a sequence of events; rather, the four innovations most likely coevolved in a parallel and disjointed fashion.

Once these core sexual-cycle themes were in place, the evolution of eukaryotic sex has featured countless prezygotic and postzygotic variations, the outcome being the segregation of

Editors: Patrick J. Keeling and Eugene V. Koonin

Additional Perspectives on The Origin and Evolution of Eukaryotes available at www.cshperspectives.org

Copyright (C) 2014 Cold Spring Harbor Laboratory Press; all rights reserved; doi: 10.1101/cshperspect.a016154

Cite this article as Cold Spring Harb Perspect Biol 2014;6:a016154 
panmictic populations into distinct species with distinctive adaptations.

For additional reviews on the evolution of sex, the interested reader is referred to Goodenough (1985), Dacks and Roger (1999), Schurko et al. (2009), Wilkins and Holliday (2009), Gross and Bhattacharya (2010), Lee et al. (2010), Perrin (2012), and Calo et al. (2013).

\section{ALTERNATION OF PLOIDY VIA CELL-CELL FUSION AND MEIOSIS}

\section{The Benefits and Challenges of Increased Genome Size and Ploidy}

Modern bacteria, and presumably their forebears, are adept at taking up DNA from outside sources (Narra and Ochman 2006). The protoeukaryote, probably at some early stage in its evolution, was also phagocytic, at least occasionally, salient evidence being its engulfment of a proteobacterium that was then domesticated as the mitochondrion. Phagocytosis in modern cells is a complex process involving hundreds of proteins (Boulais et al. 2010), but early versions can be assumed to have been less sophisticated, and cell membranes capable of engaging in phagocytosis would presumably also have been capable of engaging in cell-cell fusions, as is the case for wall-less mutants of modern bacteria (Errington 2013). It has been suggested (Rose 1983; Hickey 1982, 1993) that early cellcell fusions might have been promoted by "selfish" transposons and plasmids that incur replicative advantage in novel genomic contexts; possible evidence for this hypothesis (Keeling and Roger 1995) is the use of the $\mathrm{HO}$ endonuclease or a transposase (Barsoum et al. 2010; Rusche and Rine 2010), conscripted from ancestral transposable elements, to effect mating-type switching in several yeasts.

Cell-cell fusion generates an increase in chromosome number, and although the large size of modern eukaryotic genomes could also have been the consequence of endomitosis, it seems likely that cell-cell fusions contributed to genome expansion during protoeukaryote evolution. An alternative possibility, leading to the same outcome, is that the earliest versions of cell-cell fusion entailed the engulfment of one protoeukaryote by another, with the internalized cell membrane then either digested or fused with the host cell membrane from within.

Increases in ploidy confer indubitable benefits: The resultant redundancy allows novel sequences/functions to arise in duplicate genes without compromising existing pathways, and recessive nonadaptive alleles, masked but carried through time, may prove to be adaptive in future contexts. Another potential benefit of cell-cell fusion is hybrid fitness: If, as seems likely, there existed a variety of fledgling protoeukaryotes in the population that eventually gave rise to the LECA, then their fusion would be expected to have yielded more gene-rich and occasionally more successful lineages.

Increases in genome size/ploidy are expected to eventually become deleterious, however, one challenge being to organize a successful mitosis, another to regulate appropriate levels of gene expression. Hence, there would presumably have been positive selection for the acquisition of mechanisms to maintain copy number at a manageable size.

In recent studies, a broad panel of Saccharomyces cerevisiae and Saccharomyces paradoxus strains were tested as haploids and diploids under diverse conditions (Zorgo et al. 2013). For about half of the conditions tested in which there was a difference (such as growth with rapamycin or phleomycin), haploids were more fit, whereas for the other half (such as exposure to heat or ethanol), diploids had increased fitness. Which ploidy state was less fit was highly correlated between the two species that are diverged over several million years. These findings suggest that the ability to interconvert from haploid to diploid and back again might be beneficial when conditions shift from those favoring the haploid state to those favoring the diploid state (or vice versa). Thus, sexual reproduction might confer benefits for organisms just by enabling these rapid ploidy transitions, independent of any role in shuffling genetic composition by recombination, with endoreplication being another avenue. That said, the ability to toggle from haploid to diploid and back again is dependent on a mechanism for ploidy 
Origins of Eukaryotic Sexual Reproduction

reduction, which, in modern eukaryotes, entails meiotic or parasexual processes.

\section{PARASEXUALITY}

In the following sections, in which we consider the origins and evolution of parasexual and meiosis-based sexual cycles, we use as examples modern organisms whose mating-type-based sexual differentiation is already established. In subsequent sections we will consider how sexual differentiation itself might have originated and evolved.

\section{Parasexuality in Aspergillus}

As one must walk before one can run, the fusion of cells may have led to early parasexual cycles from which true meiotic sexual cycles evolved at a later time. We know a great deal about extant parasexual cycles from the classic work of Pontecorvo on the filamentous fungus Aspergillus nidulans in the 1950s, and these can provide insight into both possible ancestral states as well as more recent derived states given that parasexuality, like asexuality, is likely both an ancestral and a derived state (Pontecorvo 1956).

Aspergillus has a bona fide homothallic (selfing) sexual cycle, but also undergoes a parasexual cycle under laboratory conditions: Diploids are generated from haploid progenitors by hyphal fusion and the resulting diploid then loses chromosomes randomly to return to the haploid state. Recent studies have shown that this parasexual cycle provides access to a sheltered diploid state that can serve as a capacitor for evolution (Schoustra et al. 2007): More rapidly growing variants readily arise from homozygous diploids, but not from the corresponding haploid "parent," and they are then reduced to a haploid state. The faster growing variants prove to harbor multiple recessive alleles, reciprocally epistatic, that together are beneficial but individually are deleterious, and thus they can only accumulate in the diploid and then be released during parasexual genome reduction. These studies illustrate the capacity of haploid-diploid-haploid parasexual cycles to generate genotypic and phenotypic diversity de novo.

\section{Parasexuality in Candida albicans}

We also know about an unusual parasexual cycle that is extant in the most common human fungal pathogen, Candida albicans (Bennett et al. 2005; Sherwood and Bennett 2009; Berman 2012). In this species, mating occurs between diploids when the mating-type locus is homozygous (a/a and $\alpha / \alpha)$ and the cells switch to a specialized mating cell type called opaque (Miller and Johnson 2002). Cell-cell fusion then generates tetraploid cells, and adverse media conditions stimulate random chromosome loss to return to a diploid, or near diploid, state via a parasexual process (Bennett and Johnson 2003; Forche et al. 2008). Given that Candida is embedded among sexual fungi (Butler et al. 2009), this is presumably an example of a derived parasexual state, but one can envision analogous earlier versions of genetic exchange involving cell-cell fusion followed by parasexual ploidy change from which true sexual cycles evolved via the invention of meiosis. In this view, the evolution of meiosis would have been a late step in the evolution of sexual cycles.

In the C. albicans parasexual cycle, a low level of chromosomal recombination is detected in addition to chromosome loss and assortment, and these recombination events require the function of the $C$. albicans Spoll ortholog (Forche et al. 2008), a central player in meiosis. One interpretation is that the functions of Spo11 have been reconfigured to play a mitotic, parasexual role. Alternatively, the parasexual cycle of C. albicans could involve some aspects of meiosis (such as Spo11-dependent chiasmata), but given the high rate of aneuploidy (e.g., $2 \mathrm{~N}+$ $1,2 \mathrm{~N}+2$ ) that is generated, it does not produce accurate outcomes, and might be considered something akin to a "parameiosis" (Becker and De Castro-Prado 2004; Wilkins and Holliday 2009; Heitman 2010). Studies on whether other meiotic orthologs are involved may further illuminate this interesting example of what could represent a derived state similar to an ancestral parasexual-sexual transitional intermediate.

Numerous studies have identified genes expressed exclusively in cells undergoing meiosis, generating an inventory of "meiosis-specific 
genes" (Schurko and Logsdon 2008). The C. albicans genome was reported to be missing members of this list, which would be consistent with its parasexual cycle (Tzung et al. 2001). To explore what might be required in related species, a series of Candida species that are parasexual, asexual, and fully sexual was sequenced (Butler et al. 2009). Quite remarkably, two sexual species were found to be missing key mating-type locus genes and yet remain sexually fertile. Moreover, the sexual species were missing the same key meiotic genes as C. albicans, as well as two dozen others! That the unusual sexual species Candida lusitaniae truly undergoes meiosis was documented experimentally, and thus the gene repertoire to complete meiosis is apparently more plastic than thought (Reedy et al. 2009). Quite interestingly, this sexual species produces about two-thirds euploid progeny, whereas one-third is either aneuploid or diploid, possibly because they fail to execute meiosis properly in the absence of important components. Thus, like a V8 engine missing one spark plug, or a dog with three legs, the engine or animal can run but it is not pretty. Sex in nature may be messier than when studied in the laboratory with optimized $S$. cerevisiae strains, such as SK1 (which sporulates and germinates at higher frequency than many other isolates) (Ben-Ari et al. 2006), and meiotic infidelity may in fact function as a further source of diversity generated by sexual reproduction. Alternatively, meiotic infidelity may simply be tolerated in scenarios wherein a sufficient number of viable, fit progeny are generated and/or the consequences of aneuploidy are small enough to be tolerated by the population.

\section{MEIOSIS}

An alternative view is that meiosis arose early, without prior parasexual experimentation, as a means to generate haploid progeny from a diploid progenitor. Early meiosis was likely messy and inaccurate-perhaps only somewhat better than parasexual changes in ploidy-with more accurate mechanisms evolving subsequently. Like parasexuality, meiosis also serves as a mechanism to purge deleterious mutations from the genome and also reveals recessive alleles in haploid progeny of a heterozygous diploid progenitor. The return to the diploid state may have initially entailed endoreplication, with cellcell fusion mechanisms evolving later. Advantages of meiosis compared with parasexual mechanisms are fidelity and more extensive intrachromosomal recombination, at least for the forms of meiosis that are extant today.

In either view, the enzymes and machinery for meiosis presumably evolved from a core set of DNA-manipulating enzymes brought in and modified as needed from prokaryotic forebears, including both bacterial and archaeal lineages (Marcon and Moens 2005). We see this evolutionary history quite clearly in the case of Spo11 (Klapholz et al. 1985; Wagstaff et al. 1985), which introduces the DNA doublestrand breaks (DSBs) that provoke meiotic recombination (Cao et al. 1990; Keeney et al. 1997; Schurko and Logsdon 2008). Spo11 is derived from an ancestral archaeal topoisomerase VI homolog that became included in the protoeukaryote genome and was then adapted for meiosis (Bergerat et al. 1997). In essence, Spol1 is a topoisomerase that lost the ability to re-ligate DNA. That Spo11 was present in the LECA can be inferred by its presence in all of the major eukaryotic lineages studied thus far, with the notable exception of Dictyostelium discoidium and closely related slime molds that have apparently lost Spo11 but undergo complete meiotic sexual cycles (discussed further below).

We regard meiosis as accomplishing four functions: (1) reducing ploidy (parasexuality also accomplishes this, albeit less efficiently); (2) purging deleterious alleles (Kondrashov 1988) and unmasking advantageous recessives when meiotic products are haploid (parasexuality also does this); (3) reducing ploidy while also generating complete chromosome sets rather than incomplete or chaotic sets (the elegance of meiosis I); and (4) generating recombinant offspring via independent assortment and crossing over in heterozygotes. We focus here on meiosis, and later consider mating type and its imposition of heterozygosity on the system.

Meiosis entails chromosome segregation, and thus it is important to consider the nature 
of the chromosomes involved given that most modern prokaryotes have circular genomes. There are several reasons to suggest that protoeukaryotes had linear chromosomes, or at least that these arose when meiosis evolved. The earliest protoeukaryotes may have had only one or a few linear chromosomes encompassing the entire genome (which also necessitated the evolution of centromeres and telomeres to allow faithful segregation and protect the ends from decay). Linear chromosomes are required because crossing over between two circular chromosomes generates a circular dicentric that is unstable (the chromosome is broken if the two centromeres attach to opposite spindle microtubules). Even crossing over between one linear and one circular chromosome will yield a linear dicentric that would also be unstable. The advent of sexual crosses may well have driven the advent of the linear chromosome: An ancestral protoeukaryote might have had two circular chromosomes with centromeres; their recombination would have yielded a circular dicentric that, when subjected to incomplete breakagefusion-reunion cycles, could have given rise to linear chromosomes. Alternatively, linear chromosomes may have arisen in other ways, as has occurred in some bacteria and some organelle genomes, and predated sexual crosses.

The evolution of meiosis resulted in homolog chromosome pairing, independent assortment, chiasmata-based crossing over, and ploidy changes ( $2 \mathrm{~N}$ to $4 \mathrm{~N}$ to $2 \mathrm{~N}$ to $1 \mathrm{~N}$ ). Independent assortment produces diversity in the meiotic products of heterozygotes regardless of levels of crossing over, and chiasmata have been shown to play an additional role, aligning homologous chromosomes and providing tension on the spindle for accurate meiosis I segregation ( $\mathrm{Hi}-$ rose et al. 2011).

At a molecular genetic level, the evolution of meiosis would have entailed the following innovations: (1) mechanisms to promote breaks that stimulate meiotic recombination frequencies to higher levels than mitotic recombination frequencies; (2) crossovers that occur between homologs and not between sister chromatids; (3) DNA replication stimulated at meiosis I and inhibited at meiosis II; and (4) homolog synap- sis and the persistence of sister-chromatid cohesion through meiosis I into meiosis II.

There are at least two models for the promotion of recombination between homologs versus sister chromatids. In model $\mathrm{A}, 2 \mathrm{~N} \rightarrow 4 \mathrm{~N}$ DNA replication (hereafter meiotic replication) does not occur. Therefore, pairing can only occur between homologs (because replication is required to produce sister chromatids), and breaks stimulate a crossover between them, generate tension, and promote segregation (note that breaks might also stimulate their pairing). This is similar to repair of DNA DSBs that occurs in diploid fungal and human cells in the G1 phase of the cell cycle before DNA replication (Takata et al. 1998).

In model $\mathrm{B}$, if we allow meiotic replication of the $2 \mathrm{~N}$ to $4 \mathrm{~N}$ state, there are now both chromosome homologs and sister chromatids. Even without chromosome alignment and synapsis, DNA DSBs can still be repaired via either the homolog chromatid or the sister chromatid. If this occurs with the homolog, tension will be generated on the meiotic spindle, whereas if recombination occurs with the sister chromatid, tension will not be generated (tension is generated when the centromeres of the homologs attach to microtubules from different spindle pole bodies/centrosomes; when this does not occur, segregation is aborted [Nicklas 1997]). So even if there were, for example, 10 breaks per chromosome, and there were a 10:1 preference for repair with the sister chromatid versus the homolog chromatid, that single crossover per chromosome would achieve the required tension.

Either starting point could evolve into a more efficient system that reduces recombination with the sister chromatid and/or promotes recombination with the homolog. Why then even include the meiotic replication step? Because the key events in a modern meiosis I, including breaks and repair, occur in a $4 \mathrm{~N}$ context, it is difficult to speculate about original conditions, but one certain outcome is that more meiotic progeny are produced (four instead of two), and in many biological settings brood size matters. The chances are also increased that there will be at least one viable spore product given 
that meiosis was doubtless less accurate ab initio than it later evolved to be.

Perhaps the most interesting hypothesis for why replication occurs before meiotic recombination in meiosis I is that in the pre-Spo11 era, the sister-chromatid copies served as the source of DSBs. DSBs are formed by replication of nicked DNA, in which the nicks might have been incurred by UV or gamma rays before Spo11, and DSBs (but not nicks) are potent stimulators of homologous recombination. Such a model is supported by the finding that the meiotic defects of S. cerevisiae spo11 mutants can be in part suppressed by gamma irradiation, suggesting that random DSBs can suffice to enhance meiotic crossovers and increase spore viability and germination (Thorne and Byers 1993; Celerin et al. 2000). Notably, other types of DNA lesions, such as abasic sites or nicks generated by DNA deaminase acting to convert cytosine to uracil (a substrate for uracil $N$-glycosylase), can restore meiotic recombination in mutants of the fission yeast Schizosaccharomyces pombe lacking Spo11 (rec12) without generating DSBs (Pauklin et al. 2009). These studies show that one can take the activation-induced deaminase (AID) enzyme that stimulates somatic hypermutation of antibody-encoding genes in immune cells, express it heterologously in fission yeast mutants lacking Spo11, and the resultant DNA lesions and their processing promote meiotic recombination, restore fidelity of chromosome segregation, and enhance spore viability and germination frequency.

A key innovation-indeed, the hallmark of meiosis-was synapsis between homologs. For this to succeed, mechanisms promoting sister chromatid cohesion were required. The unique feature of meiosis compared with mitosis is meiosis I in which chromosome homologs rather than sister chromatids segregate in a reductional division (Watanabe 2004; Wood et al. 2010). For this to occur, there are three key steps: (1) homologs must synapse, and this is typically driven by Spo11-dependent DSBs that provoke meiotic recombination; (2) the kinetochores from sister chromatids both attach to microtubules from the same spindle pole body via monopolar attachment; and (3) cohesion of chro- mosome arms is released but cohesion near the kinetochores persists to allow homologs to segregate. Each of these steps is mediated by meiosis-specific elements that evolved from ancestral roles: step 1 by Spol1 (a former archael topoisomerase); step 2 by Rec8 (S. pombe and other organisms) or the monopolin complex (S. cerevisiae) and temporal orchestration of microtubule-kinetochore interactions to promote monopolar rather than bipolar spindle attachment (Miller et al. 2012); and step 3 by Rec8 again (and other related cohesins in many organisms) as the meiosis-specific cohesins that replace mitotic cohesins (Parisi et al. 1999) and persist at kinetochores through meiosis I. Rec8 and related meiotic cohesins can also serve additional roles, including the enhancement of synapsis and recruitment of recombination factors (Wilkins and Holliday 2009).

That Spol1 and its associated cofactors are nearly universal throughout eukaryotes suggests that it was already a key element in the meiosis of the LECA. The one known exception is the slime mold D. discoideum and closely related species, which appear to have complete sexual cycles including meiosis but which lack Spo11 (Eichinger et al. 2005; Sucgang et al. 2011). This implies that the slime molds are a derived rather than ancestral state, but that said, it seems likely that other types of DNA damaging pathways have taken the place of Spol1 in slime molds. These novel pathways remain to be identified, and may also function in aspects of meiosis in other extant organisms. Elucidating how Spo11-independent meiotic recombination can occur should shed further light on possible early steps in the evolution in meiosis in a pre-Spo11 era that presumably existed in the posited transition from parasexual to sexual experimentation in the extinct protoeukaryote lineages that antedate the LECA.

It is worth noting explicitly that original versions of meiosis may have taken tetraploids to diploids rather than diploids to haploids, or octoploids to tetraploids for that matter because the key metric is ploidy transition rather than absolute ploidy level; there is no basis to the claim that the original meiotic products were haploid, other than the parsimony argu- 
ment that because they are so now then they may also have been so when they originated. That said, haploid meiotic products have the advantage of allowing the "purging" of deleterious alleles and the "unmasking" of potentially adaptive recessive alleles, both clear benefits of the modern version of meiosis.

\section{REGULATION OF CELL-CELL FUSION}

\section{Restricting Cell-Cell Fusion to "Self" Interactions}

Although the initial pressure to develop meiosis may have been to effect ploidy reduction, the process evolved into something far more sophisticated: a mechanism to generate complete chromosome sets during meiosis I and then halve their ploidy during meiosis II. In order for haploid products to recapitulate these events, and hence again avail themselves of the advantages of diploidy, they must in turn fuse together to create diploids that are both capable of meiosis and precluded from undergoing additional fusion events. Indiscriminate cell-cell fusions, although they may have generated important novelties during early protoeukaryotic evolution, generate disparate chromosome complements that are toxic to a successful meiosis. Hence the invention of meiosis puts pressure on the development of mechanisms wherein haploid cells first recognize other haploid cells with the same chromosome complement, and then fuse with them selectively.

Recognition of self is not, of course, a eukaryotic novelty. The widespread occurrence of biofilm formation and quorum sensing in modern bacteria (Vlamakis et al. 2013) and archaea (Koerdt et al. 2010; Frols 2013) suggests that the forebears of protoeukaryotes likely engaged in such self-recognition behaviors as well. Modern prokaryotic systems feature the secretion of lineage-specific extracellular matrix materials and small molecules; their receptor-mediated perception then triggers signal-transduction cascades that modulate growth and metabolism. Hence self-recognition modules presumably existed in the protoeukaryotic gene pool that, with evolutionary tinkering, allowed like-like hap- loid cell adherence to trigger intracellular signals that elicited the conditions for cell-cell fusion.

Modern sexual recognition systems are overwhelmingly prezygotic_cells recognize "self" via pheromones or cell-surface molecules that stimulate zygotic cell fusion-but postzygotic mechanisms have also evolved that permit cells to monitor how similar their chromosomal sequences are with respect to their fusion partner. For example, when different yeast species are induced to fuse with each other, their hybrid is unable to proceed smoothly through meiosis, even if all the chromosomes are colinear and syntenic, because a higher level of DNA mismatches provokes the mismatch repair machinery to abort meiotic recombination events, and spores fail to germinate (Chambers et al. 1996; Hunter et al. 1996). That said, there are examples in which hybrids that have formed from crossspecies cell-cell fusions have ultimately given rise to new species, such as the posited origin of $S$. cerevisiae from an ancestral whole genome duplication event following fusion of two related, but different, yeast species (Wolfe and Shields 1997; Scannell et al. 2006). Exciting recent studies report adaptive changes that occur in the genomes of such cross-species hybrid yeasts isolated and passaged under laboratory conditions; genome rearrangements arise repeatedly and independently (Dunn et al. 2013).

\section{Limiting Expression of Recognition/Fusion Molecules to Particular Conditions}

In haploid eukaryotic microorganisms, the display of self-recognition/fusion molecules is usually not constitutive. Instead, postmeiotic cells first enter a mitotic phase and multiply until receiving an exogenous signal. In yeasts and Volvox, a pheromone is detected; in most other microbes some kind of environmental stress, such as the depletion of essential nutrients in the environment (often nitrogen), is detected (Sager and Granick 1954; Ueno et al. 2001). Detection of such signals then induces the expression of genes encoding the necessary components for adhesion and fusion, where cells displaying such competence are called gametes. Again, such a system need not be con- 
sidered a eukaryotic novelty because prokaryotes also limit production of their biofilm and quorum-sensing components to particular environmental circumstances ( $\mathrm{Ng}$ and Bassler 2009).

Pheromone-induced control over mating competence has the advantage of requiring that a potential mating partner is nearby. A stress-imposed elicitation of mating competence has the effect of enabling the mitotic progeny of meiotic products to first test out their haploid genomes in the environment into which they germinate, with deleterious alleles purged and adaptive alleles/genomes spreading into the population. The survivors can then avail themselves of the benefits of entering the diploid state when the environment is no longer supportive. Life cycles with extended haploid phases and occasional diploid phases are often said to engage in facultative sex, as contrasted with the obligate sex that characterizes most land plants and animals. The conditions that elicit facultative sex may be difficult to identify, meaning that sexual interactions may occur in the wild that investigators have thus far failed to recapitulate in the laboratory (Fritz-Laylin et al. 2010; Grimsley et al. 2010; Halary et al. 2011; Lahr et al. 2011).

Systems that detect an appropriate exogenous signal-hormonal and/or environmental-and elicit downstream gametic differentiation are expected to include receptor components that are coupled to the regulation of gene expression via signal-transduction cascades. Such pathways are well understood in the fungal response to pheromones (Di Segni et al. 2011; Kim et al. 2012), but they have thus far remained more elusive in microbes that respond to environmental cues because the expression of many non-sex-related genes is also influenced by environmental stress.

\section{THE ORIGINS OF MATING TYPE}

The original self-recognition molecules in protoeukaryotic gametes might have engaged in homotypic interactions, like present-day cadherins that adhere to one another (Hulpiau and van Roy 2009). Alternatively, the interac- tions might have been heterotypic, like present-day integrins that adhere to intercellular adhesion molecules (ICAMs) (Kim et al. 2011).

Any heterotypic recognition/adhesion pairs (hereafter $\mathrm{H} 1 / \mathrm{H} 2$ ) in a protoeukaryote would be candidates for the next posited stage in the origins of sex, namely, the exclusive expression of $\mathrm{H1}$ in gametes that we will generically call plus mating type and exclusive expression of $\mathrm{H} 2$ in gametes that we will call minus mating type. The regulatory system that limits expression of mating-related genes to one or the other type of gamete will be called the mating-typedetermination (MTD) system, with that leading to plus mating type called $\mathrm{MTD}_{\mathrm{P}}$ and the other leading to minus mating type called $\mathrm{MTD}_{\mathrm{M}}$.

A simple model for the incarnation of mating type might go as follows. (1) The original MTD was a transcription factor that, in response to the appropriate exogenous signal, activated expression of unlinked genes encoding $\mathrm{H} 1$ and $\mathrm{H} 2$ by binding to common upstream sites. (2) A copy of the MTD gene mutated such that the DNA-binding motif of its protein product was altered, converting it to $\mathrm{MTD}_{\mathrm{P}}$. (3) Mutations altered the upstream sequence of the gene encoding $\mathrm{H} 1$ to match this new $\mathrm{MTD}_{\mathrm{P}}$ configuration so that $\mathrm{MTD}_{\mathrm{P}}$ now induced only $\mathrm{H} 1$ expression. (4) The original version of MTD continued to activate expression of $\mathrm{H} 2$; because it is now different from $\mathrm{MTD}_{\mathrm{P}}$, it is designated $\mathrm{MTD}_{\mathrm{M}}$.

The outcome would then be that, with environmental stress, plus gametes displaying $\mathrm{H} 1$ will only adhere and fuse with minus gametes expressing $\mathrm{H} 2$. Because the $\mathrm{MTD}_{\mathrm{P}}$ and $\mathrm{MTD}_{\mathrm{M}}$ alleles now elicit the formation of two different kinds of gametes, we can say that they specify mating type and that their chromosomal locus defines the mating-type (MT) locus, such that we speak of the MT-plus and MT-minus loci. And because the MT loci are allelic, independent assortment would generate two plus and two minus haploid products at each meiosis.

That there would be selection for and eventual fixation of such a heterozygous system is inherent in the argument most often offered as the "reason" for eukaryotic sex: its promotion of outcrossing and hence the generation of nov- 
el genotypes via independent assortment and/ or crossing over. Although meiosis operates correctly when the chromosomes are fully isogenic, imposing the requirement that the fusing gametes be heterozygous, at least at the MT-plus/ MT-minus locus, introduces a whole new role for meiosis in the sexual life cycle.

Outcrossing can carry a proximal cost as well, namely, the disruption of adaptive genotypes during independent assortment and crossing over (Maynard Smith 1976; Otto and Gerstein 2006; Goodenough et al. 2007; Escobar et al. 2008), a cost that can be overridden by a shift to asexuality/homothallism/inbreeding or by the occurrence of speciation. Clearly, however, this cost has not overridden the benefits of genetic shuffling within a population to generate phenotypes adapted to an ever-changing environment, as attested by the retention of the meiotic option in most if not all major eukaryotic lineages for more than a billion years.

A number of theoretical studies, cited in Hadjivasiliou et al. (2013), have posited that the uniparental inheritance of organelles, considered in a later section of this review, preceded, and led to, the instantiation of mating types. Hadjivasiliou et al. (2013) present arguments against this hypothesis, concluding that mating-type systems would have been buttressed but are not likely to have been initiated by uniparental systems.

\section{MODERN VERSIONS OF MTD SYSTEMS AND MT LOCI}

Two MTD systems are well characterized in modern eukaryotic microbes, and both prove to use a variation on our simple model. Instead of there being two MTD alleles, there exists a single determinant which, when expressed, dictates the differentiation of one mating type. When this determinant is absent, the second mating type differentiates "by default."

In the Chlamydomonas reinhardtii version of this arrangement (Goodenough et al. 2007), the MID gene encodes a transcription factor in the RWP-RK family (Lin and Goodenough 2007; Konishi and Yanagisawa 2013). The MTminus locus carries a copy of $M I D$, whereas it is absent from the MT-plus locus. Any organism expressing an endogenous or transgenic MID gene differentiates as a minus gamete, switching on minus-specific genes and not expressing plus-specific genes, whether or not the MTplus locus is also present. When MID is absent or mutant, organisms differentiate as plus (Ferris and Goodenough 1997; Lin and Goodenough 2007). Interestingly, an analogous system also operates in mammals. The Y chromosome $S R Y$ gene, encoding a Sox transcription factor, dictates male differentiation when present; female differentiation occurs in its absence (Sekido and Lovell-Badge 2009).

The $S$. cerevisiae version is similar except that two tightly linked genes in the MAT $\alpha$ locus, $\alpha 1$ and $\alpha 2$, collectively perform the same function as MID: The $\alpha 1$ product (an $\alpha$-domain transcription factor) induces $\alpha$-specific genes and the $\alpha 2$ product (a homeobox transcription factor) represses a-specific genes $(\mathrm{Ni}$ et al. 2011). The MATa locus lacks the $\alpha 1$ and $\alpha 2$ genes; cells inheriting MATa, or cells carrying a deletion of MAT, differentiate as a gametes.

Modern microbial gamete-differentiation programs have expanded well beyond our minimalist model-many plus/a-specific genes are induced in addition to the $\mathrm{H} 1$ equivalent, and many minus $/ \alpha$-specific genes are induced in addition to the $\mathrm{H} 2$ equivalent (Mata et al. 2007; Snell and Goodenough 2008; van Werven et al. 2012)—but the core principle holds. The frequent turnover and convergent evolution of MT systems indicates the importance and impact of variations in this system.

The MT loci of yeasts contain only two contiguous transcription-factor genes; the genes encoding sexual traits are found elsewhere in the genome and regulated in trans. In several other organisms, MT loci are more complex (Ferris et al. 2002, 2010; Metin et al. 2010; Umen 2011; De Hoff et al. 2013): As in the yeasts, most genes encoding sexual traits are not linked to MT and are regulated in trans, but some sexrelated genes have come to reside in MT along with the mating-type determinant(s). These genes are typically interspersed with non-sexrelated genes, and their linkage to MTDs is established via some form of recombinational re- 
pression. Extreme examples of this phenomenon are the dimorphic (e.g., XY and WZ) sex chromosomes of mammals, birds, and some land plants, in which recombination is repressed by reducing the DNA homology needed for synapsis to short pseudoautosomal regions (Waters et al. 2007; Ellegren 2011). In the fungus Cryptococcus neoformans and the green algae $C$. reinhardtii and V. carteri, numerous chromosomal rearrangements act to inhibit successful synapsis, assuring, for example, cotransmission of the MID gene and the gene encoding the $m i$ nus recognition protein in $C$. reinhardtii (Ferris et al. 2002, 2004, 2010). Although this feature of complex MT loci and sex chromosomes assures that certain sex-related genes are cotransmitted, the fact remains that most sex-related genes are dispersed throughout the genome. Hence the "purpose" of and the pressures generating such genomic differentiations are not yet clear.

In modern multicellular organisms, the MTD systems are themselves complex (Pomiankowski et al. 2004; Kimchi et al. 2007; Salz 2011), highly diverse (Haag and Doty 2005), and often labile (Charlesworth and Mank 2010), and the H1/H2 programs they specify have expanded to include control over tissue and organ differentiation and, in animals, brain and behavioral patterning.

\section{Multiple Mating Types and Homothallism}

In addition to the cost of outcrossing noted earlier, the introduction of heterozygous mating types restricts fusion partners to half the population. In most modern eukaryotes, this handicap has been assuaged by the evolution of countless systems for identifying the opposite type via pheromones and mating behaviors, enhancing the efficiency of finding a mate, but options are still limited to half the population. In some lineages, the odds have been improved by the presence of multiple mating types - three or more in Dictyostelium (Bloomfield et al. 2010, 2011), seven in Tetrahymena (Phadke et al. 2012; Cervantes et al. 2013; Umen 2013), 13 in Physarum polycephalum (Collins and Tang 1977; Clark and Haskins 2010), and often thousands in the basidiomycetes (Raper 1966) —and in these cases more encounters are sexually fertile ( $>98 \%$ in some basidiomycetes). But more outcrossing is not always better, and in basidiomycete fungi there are multiple independent transitions from the tetrapolar outcrossing species with thousands of sexes back to bipolar species with just two mating types, where it has been suggested that different environments favor outcrossing versus inbreeding sexual cycles (Heitman et al. 2013).

Yet another way to enhance the efficiency of finding a compatible mate is to dispense entirely with the requirement of different mating types for cell-cell fusion. In such unisexual species, any isolate can fuse with any other (under some conditions in the presence of a third partner that serves as a pheromone donor to trigger like-with-like cell fusion in ménage à trois matings). This strategy has been adopted by two of the most common systemic human fungal pathogens, C. neoformans and C. albicans, and also several nonfungal eukaryotic microbial pathogens (Lin et al. 2005; Heitman 2006, 2010; Poxleitner et al. 2008; Alby et al. 2009; Wendte et al. 2010; Carpenter et al. 2012).

Finally, many lineages, including algae and fungi, abandon heterothallism for homothallism, wherein a single haploid genome contains both $\mathrm{MTD}_{\mathrm{P}}$ and $\mathrm{MTD}_{\mathrm{M}}$ equivalents; these are tightly linked in the case of some filamentous ascomycetes, and unlinked in others (Vanwinkle-Swift and Burrascano 1983; Lee et al. 2010; $\mathrm{Ni}$ et al. 2011). One or the other determinant is expressed in individual gametes during the course of gametogenesis, the result being "selffertilization." Heterothallic species often have closely related homothallic counterparts ( $\mathrm{Ny}$ gren et al. 2011), indicating that this trait is susceptible to evolutionary pressures. Modern multicellular parthenogens are also known to engage in "occasional sex" (Pires-daSilva 2007; D’Souza and Michiels 2010).

\section{MATING-TYPE-REGULATED COUPLING OF DIPLOIDY TO THE FORMATION OF RESTING SPORES}

In previous sections we have suggested that the selective advantage of diploidy lies in the pres- 
ence of at least two copies of each gene, allowing complementation of recessive lethal mutations and the potential generation of novel alleles/ genes in the second copy. At some point during the evolution of protoeukaryotes, there evolved an additional and far more immediate and tangible benefit to transitions from the haploid to the diploid state, namely, restricting the formation of a resting spore to diploid cells, diploid cells, a capability that came to be controlled by mating type.

Haploid resting spores are produced by several modern bacterial lineages (Henriques and Moran 2007); they are also found in several amoeba lineages (West 2003; Chatterjee et al. 2009; Fritz-Laylin et al. 2010) and in many fungi (Feofilova et al. 2012) and algae (Hagen et al. 2002). Hence it is plausible to propose that the protoeukaryote possessed a genetic program for haploid spore differentiation that was independent of any sexual process. Sporulation programs typically entail the assembly of a novel cell wall that preserves viability in the face of noxious environmental circumstances such as high temperature, freezing, desiccation, predation (Coluccio et al. 2008), and exposure to ionizing radiation. They also impose modulation of gene expression to a minimalist "maintenance" mode and the accumulation of polysaccharide and lipid storage products for use during germination and the resumption of mitosis when conditions improve. Hence the programs that govern haploid spore formation are expected to include "spore-specific" genes that are not expressed in cycling cells and are activated at the time that the circumstances dictate the importance of shifting to a resting state.

As noted earlier, such deteriorating conditions commonly also trigger the expression of the MTD systems that control gametic recognition/fusion programs. Therefore, the stage would be set for mating type to acquire control over diploid resting-spore formation as well, the spore thereby endowed with both longterm viability and the advantages, already listed, of generating recombinant progeny via an eventual meiosis. An advantage of diploid spores could also be to promote repair of DSBs during dormancy, similar to haploid yeasts such as $S$. pombe that arrest in the G2 phase of the cell cycle to enable repair from the other sister chromatid.

In those cases in which the molecular basis for shifting to diploid resting-spore differentiation is understood in eukaryotic microbes, the transition is triggered by the formation of a heterodimeric transcription-factor complex, with subunits that we will generically designate $\mathrm{P}$ and $\mathrm{M}$ (for plus and minus). Synthesis of $\mathrm{P}$ is restricted to plus gametes and hence regulated by $\mathrm{MTD}_{\mathrm{P}}$; synthesis of $\mathrm{M}$ is restricted to minus gametes and hence regulated by $\mathrm{MTD}_{\mathrm{M}}$. Fusion of plus and minus gametes permits the formation of $\mathrm{P} / \mathrm{M}$ heterodimers, and these are uniquely capable of activating expression of diploid-specific genes (and repressing haploid-specific genes), including genes involved in restingspore formation and, at some later stage, genes involved in entering meiosis and spore germination. Importantly, it is not necessary to posit that the $\mathrm{P} / \mathrm{M}$ factor orchestrates all spore- and meiosis-related genes directly - these programs are presumably coordinated by preexisting circuits from haploid sporulation and diploid meiotic programs. Rather, $\mathrm{P} / \mathrm{M}$ is posited to initiate a cascade that permits the regulated expression of these genes during diploid-spore maturation and subsequent germination.

There is, of course, a pleasing symmetry in this arrangement in that the $\mathrm{P} / \mathrm{M}$ requirement for diploid differentiation mirrors the $\mathrm{H} 1 / \mathrm{H} 2$ requirement in the fertilization process, both being regulated by mating type. In a recent review, Perrin (2012) lifts up this feature as well, noting that "mating types have evolved to switch on the right program at the right moment."

The $\mathrm{P} / \mathrm{M}$ pairs thus far identified in microbes are usually members of the homeoprotein transcription-factor family: $\mathbf{a} 1 / \alpha 2$ in S. cerevisiae (Madhani 2007) (in which $\alpha 2$ performs "double duty," functioning as well in the haploid phase); Sxi1 $\alpha /$ Sxi2a in C. neoformans (Hull et al. 2002, 2005); bW/bE in Ustilago maydis (Schulz et al. 1990); and GSP1/GSM1 in C. reinhardtii (Lee et al. 2008a). The one known exception is that HMG-family or $\alpha$ box transcription factors drive differentiation 
in the zygotes of filamentous ascomycetes and zygomycetes (Glass et al. 1988; Fraser et al. 2007; Idnurm et al. 2008; Lee et al. 2008b), groups that lack MT-encoded/regulated homeoproteins. Whether these factors dimerize or act independently on common target promoters is not yet known. Yeast two-hybrid studies failed to detect dimerization between the SexM and SexP proteins of Phycomyces (A Idnurm, unpubl.), suggesting that novel mechanisms may operate.

An explosive expansion of homeoproteinencoding genes has accompanied the evolution of multicellularity in animals and land plants, with homeoprotein-based combinatorial control exerted over core domains of the body plan: PBC/MEIS + HOX proteins specify the anterior-posterior axis of animals (Mann and Morata 2000), and KNOX + BELL proteins specify the initiation of the moss sporophyte program (Sakakibara et al. 2013) and regulate the architecture of shoot apical meristems (Hake et al. 2004). As expanded elsewhere (Lee et al. 2008a), it is appealing to posit that the combinatorial-control "idea," originally governing the differentiation of diploid zygotic spores, was co-opted to govern the differentiation of multicellular diploids.

\section{MATING-TYPE-REGULATED TRANSMISSION OF ORGANELLE GENOMES}

\section{Theoretical Considerations}

The stages in the domestication of a proteobacterium into a mitochondrion, a seminal achievement of the protoeukaryote, are not known. However, the analysis of an ongoing domestication process - the conversion of a Synechococcus cyanobacterium into a "cyanelle" (protochloroplast) in the testate amoeba Paulinella chromatophora (Rhizaria) - is providing fascinating insights into what is entailed (Chan et al. 2011; Bodyl et al. 2012; Nowack and Grossman 2012). During the 60 million years since the estimated onset of this conversion, the genome of the endosymbiont has undergone an estimated $75 \%$ reduction in size, and roughly $1 \%$ of the amoeba's nuclear genes are of endosymbiont origin. Many of these genes encode proteins that function in photosynthesis, and presequences that target their import into the cyanelle have been identified. Hence the posited gene-transfer events that accompanied mitochondrial and chloroplast domestication are apparently being recapitulated in Paulinella.

Importantly, what is already in place in Paulinella is a mechanism to coordinate the replication of the cyanelle's DNAwith the replication of the amoeba's DNA such that, at each mitosis, each daughter cell inherits two cyanelles. Because the growth rate of free-living Synechococcus (6-12 h doubling time) far exceeds the growth rate of testate amoebas (1-3 d doubling time), the imposition of such control is presumably an early and critical event in establishing any endosymbiotic relationship, preventing the engulfed bacterium from overwhelming the host cell, and it was presumably quickly established during the protoeukaryote's acquisition of protomitochondria and protochloroplasts. Eukaryotes vary widely in numbers of mitochondria and chloroplasts per cell and in numbers of genomes per organelle, but in a given microorganism, or cell type in a multicellular organism, these values are maintained at constant levels.

The development of a sexual cycle would be expected to place such a control system in jeopardy. The fusion of gametes would generate diploid zygotes with twice the organelle- genome tally, and without some way to return to the "organelle-haploid" value, meiotic products would be "organelle-diploid" and then, in the next round, "organelle-tetraploid" and so on.

This dilemma suggests a hypothesis regarding the origin of the near-universal pattern of organelle inheritance in modern sexual eukaryotes - the uniparental (UP) transmission of organelle genomes to meiotic products. In this scenario, the solution adopted by the LECA was to (1) tag the organelles residing in plus gametes differently from the organelles residing in minus gametes, and (2) devise a system that recognizes these tags in the diploid zygote and selectively prevents one set of organelles/organelle genomes from being transmitted, thereby reestablishing the "organelle-haploid" number in all four meiotic products. By placing the tag- 
ging system under the purview of the matingtype system, the LECA would have been able to control organelle ploidy using the same system that it used to regulate nuclear ploidy, albeit the downstream mechanisms are totally different.

That modern UP systems are sensitive to organelle ploidy has been shown in C. reinhardtii. The usual pattern, described in detail below, is that chloroplast genomes from the minus parent are destroyed by nucleases in the early zygote, leading to UP inheritance of plus genomes. However, if the zygotic input of plus chloroplast genomes is reduced, either by growth in FuDR (Wurtz et al. 1977; Matagne and Beckers 1983; Armbrust et al. 1995) or by the mat3 mutation (Gillham et al. 1987; Armbrust et al. 1995; Umen and Goodenough 2001), destruction of minus genomes is aborted and chloroplast DNA inheritance is biparental (BP).

In most modern egg/sperm systems, the egg can have millions of organelle genomes, whereas sperm are either stripped of organelles or their organelle DNA is destroyed by the zygote. Therefore, if an "organelle ploidy" system played a role in establishing UP in isogamous organisms, this consideration is clearly irrelevant to modern anisogamous organisms.

A second consequence of UP inheritance is that at each sexual generation, a uniform set of organelle genomes is exposed to natural selection in the "unmasked" haploid state, and a uniform set of organelle genomes is eliminated from the gene pool altogether. This may serve to guard against "selfish" genomes (Hurst and Werren 2001) that might otherwise infest and destroy the population, or even the species, with unregulated organelles. Again we encounter meiotic symmetry in that such "purging" functions are also a feature of meiosis.

A third consequence of a UP system is that it guards against "heteroplasmy," the presence of two or more different organelle genomes in the same organism. In a recent study, mice were artificially manipulated to be heteroplasmic for mitochondrial genomes, and they showed a number of developmental and cognitive defects (Sharpley et al. 2012); the investigators suggest that disparate OXPHOS subunits encoded by the two genomes might assemble into defective complexes.

The zygotes of budding and fission yeasts receive mitochondrial genomes from both parents and do not destroy one set (Solieri 2010); however, they carefully segregate mitochondria during the early diploid mitotic divisions such that daughter-cell clones become "homoplasmic" for one or the other input genome (Basse 2010). Similarly, C. reinhardtii meiotic products manipulated to be heteroplasmic for chloroplast genomes rapidly "sort out" to yield homoplasmic mitotic clones within 10-20 cell generations (VanWinkle-Swift 1980; Forster et al. 1980). Thus most modern eukaryotic organisms manage to acquire homoplastic organelle profiles by one means or another, suggesting that this condition is adaptive.

Countering this inference is the demonstration that in Medicago (clover) (Matsushima et al. 2008), Passiflora (Hansen et al. 2007), and Mytilus (mussel) (Jha et al. 2008), organelle inheritance is or can be biparental without known adverse consequences. Clearly there are fundamental features of UP that are not yet understood, leading us to quote a quip from Maynard Smith (1976) regarding another sex-related enigma: "One is left with the feeling that some essential feature of the situation is being overlooked."

\section{Modern UP Systems}

That UP inheritance of organelle genomes is controlled by mating type was first discovered by Sager and Tsubo (1961) in the alga C. reinhardtii: Traits encoded by chloroplast genomes and carried by plus gametes are usually transmitted to all meiotic progeny, whereas few if any of the progeny inherit traits encoded by chloroplast genomes and carried by minus gametes. Subsequent studies showed that the reciprocal is true for mitochondrial genomes: Those contributed by minus gametes are transmitted, whereas those contributed by plus gametes are not (Aoyama et al. 2006). Both systems entail DNA degradation; shortly after gamete fusion, the minus-contributed chloroplast chromosomes are destroyed by nucleases (Nishimura et al. 2002; 
Kuroiwa 2010), whereas the plus-contributed mitochondrial chromosomes are destroyed $\sim 24$ h later (Nakamura 2010). The GSP1/ GSM1 heterodimer, described above, that triggers spore development, is also required to activate these recognition/destruction programs; when disabled, inheritance of both chloroplast and mitochondrial genomes is biparental (Nishimura et al. 2012). Little is yet known about the molecular basis of the tagging systems except that the activity that serves to protect chloroplast DNA from being destroyed is evidently encoded by gene(s) in the MT-plus locus (reviewed in Goodenough et al. 1995, 2007).

In the basidiomycete $C$. neoformans, the mitochondrial genome is selectively inherited from the parent of a mating type; a small proportion of meiotic products inherit the $\alpha$ parent's mitochondrial genome or a recombinant mitochondrial genome (Xu et al. 2000; Yan and Xu 2003; Toffaletti et al. 2004). It is not known whether this process involves a selective destruction of the parental $\alpha$ mitochondrial genome (possibly via mitophagy), preferential migration of the a mating-type mitochondria into the zygote, or both (Gyawali and Lin 2011). What is known is that both the SXI1 $\alpha$ and the SXI2a homeodomain proteins that activate the $\mathbf{a} / \alpha$ zygotic program are required for UP mitochondrial inheritance (Yan et al. 2004; Yan et al. 2007), just as in the C. reinhardtii system. Recent studies also provide evidence for both prezygotic and postzygotic levels of control, with the Mat2 pheromone-response high-mobility group (HMG) factor playing a role in prezygotic marking of mitochondrial genomes (Gyawali and Lin 2013), again similar to the system in C. reinhardtii.

In the plant pathogenic basidiomycete $U$. maydis, sexual reproduction results in UP mitochondrial inheritance that is also controlled by the mating-type locus. The mating-type locus, encoding the pheromones and pheromone receptors necessary for mate recognition, occurs as two alleles. One (a1) encodes just the pheromone and pheromone receptor genes; the other (a2) encodes both of these and also two additional genes ( $\operatorname{lga} 2$ and $\mathrm{rga} 2$ ) that govern UP mitochondrial inheritance during sexual reproduction. When a 2 mutants lacking lga2 are crossed, progeny inherit mitochondria from either parent and show a higher frequency of mitochondrial recombination (Fedler et al. 2009). Correspondingly, when rga2 is expressed heterologously in a1 cells, the a 1 mitochondrial genome is now protected and again progeny inherit mitochondria from either parent. Finally, deletion of rga2 from a 2 cells results in loss of the a 2 mitochondrial genome and inheritance of mitochondria from the al parent-exactly the opposite of the pattern observed with wild-type crosses. Thus rga2 protects the host cell mitochondrial genome, whereas lga2 functions in mitochondrial destruction via a dynamin-dependent mitophagy pathway (Mahlert et al. 2009; Nieto-Jacobo et al. 2012).

Although there is as yet no information on the molecules that exert mating-type UP control in most systems, the selective destruction of one set of organelle genomes has been shown in several disparate radiations, including the chlorophytes Gonium (Setohigashi et al. 2011) and Bryopsis (Kuroiwa and Hori 1986), the ulvophyte Ulva (Kagami et al. 2008), brown algae (Motomura et al. 2010), the slime mold Physarum (Moriyama and Kawano 2010), Drosophila (DeLuca and O'Farrell 2012), the fish Orizias (Nishimura et al. 2006), and the mouse (Kaneda et al. 1995; Kuroiwa 2010; Sato and Sato 2013). Notably, in the vertebrate examples, the sperm organelles enter the egg but are quickly and selectively eliminated in the zygote in a species-specific fashion (Kaneda et al. 1995). In land plants, plastids are excluded from the sperm cell or are left behind in synergid cells during fertilization (Mogensen 1996; Liu et al 2004); mechanisms are again unknown.

\section{SEX AND SPECIATION}

A signature feature of eukaryotes is that they speciate, segregating into closely related populations that fail to respond to each other's mating cues to form zygotes (prezygotic isolation) and/or form zygotes that fail to produce a viable next generation (postzygotic isolation). Postzygotic incompatability between nuclear and mitochondrial genomes (Chou and Leu 2010) or between multiple nuclear loci (Kao et al. 2010) 
have both been shown to play a role in Saccharomyces species incompatibilities. Hence sex-related genes are integral to establishing species boundaries. As developed more fully elsewhere (Goodenough et al. 2007), it can be argued that "speciose" lineages, poised to branch into populations with separate and distinctive gene pools, are more likely to navigate long-term environmental fluctuations and hence move through time (i.e., avoid extinction) than "nonspeciose" lineages confined to more narrow niche dimensions.

A corollary of this argument is that speciose lineages are predicted to have "evolvable" prezygotic mating systems, capable of generating new dyadic combinations so that isolation barriers can be erected. An evolvable $\mathrm{H} 1 / \mathrm{H} 2$ recognition system, for example, might consist of a polysaccharide that can readily accommodate novel glycan subunits and a lectin whose active site can incur amino acid changes and still adopt a functional, and variant, fold. Examples of rapidly evolving mate-recognition systems have in fact been documented in multiple eukaryotic lineages (Palumbi 2009; Jagadeeshan et al. 2011; Nygren et al. 2012; Singh and Jagadeeshan 2012). Yeast-mating-type switching and other selfing mechanisms (Lee et al. 2010) could also have promoted speciation: Genome rearrangements and chromosomal translocations lead to postzygotic blocks to sexual reproduction, but if an individual with a rearranged genome simply switches mating type, it now has a mate with a colinear genome with whom to found a new species. Although nothing is known about the speciosity of the LECA itself, evolutionary history indicates that the tendency to speciate was instantiated early (Parfrey et al. 2011). Hence the "Why sex?" question has yet another answer: It offers the means to diversify in a eukaryote-specific fashion, one that has had spectacular outcomes.

\section{ACKNOWLEDGMENTS}

We thank Tom Petes, Kevin Roach, Alex Idnurm, Jae-Hyeok Lee, and Sue Jinks-Robertson for comments on the article, and, in particular, we thank Sue Jinks-Robertson for suggesting that the inclusion of premeiotic DNA replication as a first step of meiosis might have been to replicate across nicks and provide DNA double-strand breaks to promote meiotic recombination in the pre-Spol1 era. We also warmly acknowledge the experimental and intellectual contributions of past and present members of our laboratories. Research on sexual differentiation in the Goodenough laboratory has been supported by grants from the National Science Foundation and the National Institutes of Health, and in the Heitman laboratory by NIH/NIAID R01 grant AI50113-10 and R37 award AI39115-16.

\section{REFERENCES}

Alby K, Schaefer D, Bennett RJ. 2009. Homothallic and heterothallic mating in the opportunistic pathogen Candida albicans. Nature 460: 890-893.

Aoyama H, Hagiwara Y, Misumi O, Kuroiwa T, Nakamura S. 2006. Complete elimination of maternal mitochondrial DNA during meiosis resulting in the paternal inheritance of the mitochondrial genome in Chlamydomonas species. Protoplasma 228: 231-242.

Armbrust EV, Ibrahim A, Goodenough UW. 1995. A mating type-linked mutation that disrupts the uniparental inheritance of chloroplast DNA also disrupts cell-size control in Chlamydomonas. Mol Biol Cell 6: 1807-1818.

Barsoum E, Martinez P, Astrom SU. 2010. $\alpha 3$, a transposable element that promotes host sexual reproduction. Genes Dev 24: 33-44.

Basse CW. 2010. Mitochondrial inheritance in fungi. Curr Opin Microbiol 13: 712-719.

Becker TC, De Castro-Prado MA. 2004. Parameiosis in Aspergillus nidulans in response to doxorubicin. Folia Microbiol (Praha) 49: 699-704.

Ben-Ari G, Zenvirth D, Sherman A, David L, Klutstein M, Lavi U, Hillel J, Simchen G. 2006. Four linked genes participate in controlling sporulation efficiency in budding yeast. PLoS Genet 2: e195.

Bennett RJ, Johnson AD. 2003. Completion of a parasexual cycle in Candida albicans by induced chromosome loss in tetraploid strains. EMBO J 22: 2505-2515.

Bennett RJ, Miller MG, Chua PR, Maxon ME, Johnson AD. 2005. Nuclear fusion occurs during mating in Candida albicans and is dependent on the KAR3 gene. Mol Microbiol 55: 1046-1059.

Bergerat A, de Massy B, Gadelle D, Varoutas PC, Nicolas A, Forterre P. 1997. An atypical topoisomerase II from Archaea with implications for meiotic recombination. $\mathrm{Na}$ ture 386: 414-417.

Berman J. 2012. Candida albicans. Curr Biol 22: R620-R622.

Bloomfield G. 2011. Genetics of sex determination in the social amoebae. Dev Growth Differ 53: 608-616.

Bloomfield G, Skelton J, Ivens A, Tanaka Y, Kay RR. 2010. Sex determination in the social amoeba Dictyostelium discoideum. Science 330: 1533-1536. 
U. Goodenough and J. Heitman

Bodyl A, Mackiewicz P, Gagat P. 2012. Organelle evolution Paulinella breaks a paradigm. Curr Biol 22: R304-R306.

Boulais J, Trost M, Landry CR, Dieckmann R, Levy ED, Soldati T, Michnick SW, Thibault P, Desjardins M. 2010. Molecular characterization of the evolution of phagosomes. Mol Syst Biol 6: 423.

Brawley SH, Johnson LE. 1992. Gametogenesis, gametes and zygotes: An ecological perspective on sexual reproduction in the algae. Brit Phycol J 27: 233-252.

Butler G, Rasmussen MD, Lin MF, Santos MA, Sakthikumar S, Munro CA, Rheinbay E, Grabherr M, Forche A, Reedy JL, et al. 2009. Evolution of pathogenicity and sexual reproduction in eight Candida genomes. Nature 459: $657-662$.

Calo S, Billmyre RB, Heitman J. 2013. Generators of phenotypic diversity in the evolution of pathogenic microorganisms. PLOS Pathog 9: e1003181.

Cao L, Alani E, Kleckner N. 1990. A pathway for generation and processing of double-strand breaks during meiotic recombination in S. cerevisiae. Cell 61: 1089-1101.

Carpenter ML, Assaf ZJ, Gourguechon S, Cande WZ. 2012. Nuclear inheritance and genetic exchange without meiosis in the binucleate parasite Giardia intestinalis. J Cell Sci 125: 2523-2532.

Celerin M, Merino ST, Stone JE, Menzie AM, Zolan ME. 2000. Multiple roles of Spo11 in meiotic chromosome behavior. EMBO J 19: 2739-2750.

Cervantes MD, Hamilton EP, Xiong J, Lawson MJ, Yuan D, Hadjithomas M, Miao W, Orias E. 2013. Selecting one of several mating types through gene segment joining and deletion in Tetrahymena thermophila. PLoS Biol 11: e1001518.

Chambers SR, Hunter N, Louis EJ, Borts RH. 1996. The mismatch repair system reduces meiotic homeologous recombination and stimulates recombination-dependent chromosome loss. Mol Cell Biol 16: 6110-6120.

Chan CX, Gross J, Yoon HS, Bhattacharya D. 2011. Plastid origin and evolution: New models provide insights into old problems. Plant Physiol 155: 1552-1560.

Charlesworth D, Mank JE. 2010. The birds and the bees and the flowers and the trees: Lessons from genetic mapping of sex determination in plants and animals. Genetics 186: 9-31.

Chatterjee A, Ghosh SK, Jang K, Bullitt E, Moore L, Robbins PW, Samuelson J. 2009. Evidence for a "wattle and daub" model of the cyst wall of entamoeba. PLoS Pathog 5: e1000498.

Chou J-Y, Leu J-Y. 2010. Speciation through cytonuclear incompatibility: Insights from yeast and implications for higher eukaryotes. Bioessays 32: 401-411.

Clark J, Haskins EF. 2010. Reproductive systems in the myxomycetes: A review. Mycosphere 1: 337-353.

Collins OR, Tang HC. 1977. New mating types in Physarum polycephalum. Mycologia 69: 421-423.

Coluccio AE, Rodriguez RK, Kernan MJ, Neiman AM. 2008. The yeast spore wall enables spores to survive passage through the digestive tract of Drosophila. PLoS ONE 3: e2873.

Dacks J, Roger AJ. 1999. The first sexual lineage and the relevance of facultative sex. J Mol Evol 48: 779-783.
De Hoff PL, Ferris P, Olson BJSC, Miyagi A, Geng S, Umen JG. 2013. Species and population level molecular profiling reveals cryptic recombination and emergent asymmetry in the dimorphic mating locus of $C$. reinhardtii. PLoS Genet 9: e1003724.

DeLuca SZ, O'Farrell PH. 2012. Barriers to male transmission of mitochondrial DNA in sperm development. Dev Cell 22: 660-668.

Di Segni G, Gastaldi S, Zamboni M, Tocchini-Valentini GP. 2011. Yeast pheromone receptor genes STE2 and STE3 are differently regulated at the transcription and polyadenylation level. Proc Natl Acad Sci 108: 17082-17086.

D'Souza TG, Michiels NK. 2010. The costs and benefits of occasional sex: Theoretical predictions and a case study. $J$ Hered 101: S34-S41.

Dunn B, Paulish T, Stanbery A, Piotrowski J, Koniges G, Kroll E, Louis EJ, Liti G, Sherlock G, Rosenzweig F. 2013. Recurrent rearrangement during adaptive evolution in an interspecific yeast hybrid suggests a model for rapid introgression. PLoS Genet 9: e1003366.

Eichinger L, Pachebat JA, Glockner G, Rajandream MA, Sucgang R, Berriman M, Song J, Olsen R, Szafranski K, $\mathrm{Xu} \mathrm{Q}$, et al. 2005. The genome of the social amoeba Dictyostelium discoideum. Nature 435: 43-57.

Ellegren H. 2011. Sex-chromosome evolution: Recent progress and the influence of male and female heterogamety. Nat Rev Genet 12: 157-166.

Errington J. 2013. L-form bacteria, cell walls and the origins of life. Open Biol 3: 120143.

Escobar JS, Nicot A, David P. 2008. The different sources of variation in inbreeding depression, heterosis and outbreeding depression in a metapopulation of Physa acuta. Genetics 180: 1593-1608.

Fedler M, Luh KS, Stelter K, Nieto-Jacobo F, Basse CW. 2009. The a2 mating-type locus genes lga 2 and rga2 direct uniparental mitochondrial DNA (mtDNA) inheritance and constrain mtDNA recombination during sexual development of Ustilago maydis. Genetics 181: 847-860.

Feofilova EP, Ivashechkin AA, Alekhin AI, Sergeeva Ia E. 2012. Fungal spores: Dormancy, germination, chemical composition, and role in biotechnology (review). Prikl Biokhim Mikrobiol 48: 5-17.

Ferris PJ, Goodenough UW. 1997. Mating type in Chlamydomonas is specified by mid, the minus-dominance gene. Genetics 146: 859-869.

Ferris PJ, Armbrust EV, Goodenough UW. 2002. Genetic structure of the mating-type locus of Chlamydomonas reinhardtii. Genetics 160: 181-200.

Ferris P, Olson BJ, De Hoff PL, Douglass S, Casero D, Prochnik S, Geng S, Rai R, Grimwood J, Schmutz J, et al. 2010. Evolution of an expanded sex-determining locus in Volvox. Science 328: 351-354.

Forche A, Alby K, Schaefer D, Johnson AD, Berman J, Bennett RJ. 2008. The parasexual cycle in Candida albicans provides an alternative pathway to meiosis for the formation of recombinant strains. PLoS Biol 6: e110.

Forster JL, Grabowy CT, Harris EH, Boynton JE, Gillham NW. 1980. Behavior of chloroplast genes during the early zygotic divisions of Chlamydomonas reinhardtii. Curr Genet 1: 137-153. 
Fraser JA, Diezmann S, Subaran RL, Allen A, Lengeler KB, Dietrich FS, Heitman J. 2004. Convergent evolution of chromosomal sex-determining regions in the animal and fungal kingdoms. PLoS Biol 2: e384.

Fraser JA, Stajich JE, Tarcha EJ, Cole GT, Inglis DO, Sil A, Heitman J. 2007. Evolution of the mating type locus: Insights gained from the dimorphic primary fungal pathogens Histoplasma capsulatum, Coccidioides immitis, and Coccidioides posadasii. Eukaryot Cell 6: 622-629.

Fritz-Laylin LK, Prochnik SE, Ginger ML, Dacks JB, Carpenter ML, Field MC, Kuo A, Paredez A, Chapman J, Pham J, et al. 2010. The genome of Naegleria gruberi illuminates early eukaryotic versatility. Cell 140: 631 642.

Frols S. 2013. Archaeal biofilms: Widespread and complex. Biochem Soc Trans 41: 393-398.

Gillham NW, Boynton JE, Johnson AM, Burkhart BD. 1987. Mating type linked mutations which disrupt the uniparental transmission of chloroplast genes in Chlamydomonas. Genetics 115: 677-684.

Glass NL, Vollmer SJ, Staben C, Grotelueschen J, Metzenberg RL, Yanofsky C. 1988. DNAs of the two mating-tye alleles of Neurospora crassa are highly dissimilar. Science 241: $570-573$.

Goodenough UW. 1985. Origins and evolution of eukaryotic sex. In Origins and Evolution of Sex (ed. Halvorson HO, Monroy A), pp. 123-140. Alan R. Liss, New York.

Goodenough UW, Armbrust EV, Campbell AM, Ferris PJ. 1995. Molecular genetics of sexuality in Chlamydomonas Annu. Rev Plant Phys 46: 21-44.

Goodenough U, Lin H, Lee JH. 2007. Sex determination in Chlamydomonas. Semin Cell Dev Biol 18: 350-361.

Grimsley N, Pequin B, Bachy C, Moreau H, Piganeau G. 2010. Cryptic sex in the smallest eukaryotic marine green alga. Mol Biol Evol 27: 47-54.

Gross J, Bhattacharya D. 2010. Uniting sex and eukaryote origins in an emerging oxygenic world. Biol Direct 5: 53 .

Gyawali R, Lin X. 2011. Mechanisms of uniparental mitochondrial DNA inheritance in Cryptococcus neoformans. Mycobiology 39: 235-242.

Gyawali R, Lin X. 2013. Prezygotic and postzygotic control of uniparental mitochondrial DNA inheritance in Cryptococcus neoformans. mBio 4: $\mathrm{e} 00112-\mathrm{e} 00113$.

Haag ES, Doty AV. 2005. Sex determination across evolution: Connecting the dots. PLoS Biol 3: e21.

Hadjivasiliou Z, Lane N, Seymour RM, Pomiankowski A. 2013. Dynamics of mitochondrial inheritance in the evolution of binary mating types and two sexes. Proc $R$ Soc Lond B 280: 1-8.

Hagen C, Siegmund S, Braune W. 2002. Ultrastructural and chemical changes in the cell wall of Haematococcus pluvalis (Volvocales, Chlorophyta) during aplanospore formation. Eur J Phycol 37: 217-226.

Hake S, Smith HM, Holtan H, Magnani E, Mele G, Ramirez J. 2004. The role of knox genes in plant development. Annu Rev Cell Dev Biol 20: 125-151.

Halary S, Malik SB, Lildhar L, Slamovits CH, Hijri M, Corradi N. 2011. Conserved meiotic machinery in Glomus spp., a putatively ancient asexual fungal lineage. Genome Biol Evol 3: 950-958.
Hansen AK, Escobar LK, Gilbert LE, Jansen RK. 2007. Paternal, maternal, and biparental inheritance of the chloroplast genome in Passiflora (Passifloraceae): Implications for phylogenetic studies. Am J Bot 94: 42-46.

Heitman J. 2006. Sexual reproduction and the evolution of microbial pathogens. Curr Biol 16: R711-R725.

Heitman J. 2010. Evolution of eukaryotic microbial pathogens via covert sexual reproduction. Cell Host Microbe 8: 86-99.

Heitman J, Sun S, James TY. 2013. Evolution of fungal sexual reproduction. Mycologia 105: 1-27.

Henriques AO, Moran CP Jr. 2007. Structure, assembly, and function of the spore surface layers. Annu Rev Microbiol 61: $555-588$.

Hickey DA. 1982. Selfish DNA: A sexually-transmitted nuclear parasite. Genetics 101: 519-531.

Hickey DA. 1993. Molecular symbionts and the evolution of sex. J Hered 84: 410-414.

Hirose Y, Suzuki R, Ohba T, Hinohara Y, Matsuhara H, Yoshida M, Itabashi Y, Murakami H, Yamamoto A. 2011. Chiasmata promote monopolar attachment of sister chromatids and their co-segregation toward the proper pole during meiosis I. PLoS Genet 7: e1001329.

Hull CM, Davidson RC, Heitman J. 2002. Cell identity and sexual development in Cryptococcus neoformans are controlled by the mating-type-specific homeodomain protein Sxil $\alpha$. Genes Dev 16: 3046-3060.

Hull CM, Boily MJ, Heitman J. 2005. Sex-specific homeodomain proteins Sxil $\alpha$ and Sxi2a coordinately regulate sexual development in Cryptococcus neoformans. Eukaryot Cell 4: 526-535.

Hulpiau P, van Roy F. 2009. Molecular evolution of the cadherin superfamily. Int J Biochem Cell Biol 41: 349-369.

Hunter N, Chambers SR, Louis EJ, Borts RH. 1996. The mismatch repair system contributes to meiotic sterility in an interspecific yeast hybrid. EMBO J 15: 1726-1733.

Hurst GD, Werren JH. 2001. The role of selfish genetic elements in eukaryotic evolution. Nat Rev Genet 2: $597-$ 606.

Idnurm A, Walton FJ, Floyd A, Heitman J. 2008. Identification of the sex genes in an early diverged fungus. Nature 451: $193-196$.

Jagadeeshan S, Haerty W, Singh RS. 2011. Is speciation accompanied by rapid evolution? Insights from comparing reproductive and nonreproductive transcriptomes in Drosophila. Int J Evol Biol 2011: 595121.

Jha M, Cote J, Hoeh WR, Blier PU, Stewart DT. 2008. Sperm motility in Mytilus edulis in relation to mitochondrial DNA polymorphisms: Implications for the evolution of doubly uniparental inheritance in bivalves. Evolution 62: 99-106.

Kagami Y, Mogi Y, Arai T, Yamamoto M, Kuwano K, Kawano S. 2008. Sexuality and uniparental inheritance of chloroplast DNA in the isogamous green alga Ulva compressa (ulvophyceae). J Phycol 44: 691-702.

Kaneda H, Hayashi J, Takahama S, Taya C, Lindahl KF, Yonekawa H. 1995. Elimination of paternal mitochondrial DNA in intraspecific crosses during early mouse embryogenesis. Proc Natl Acad Sci 92: 4542-4546.

Kao KC, Schwartz K, Sherlock G. 2010. A genome-wide analysis reveals no nuclear Dobzhansky-Muller pairs of 
determinants of speciation between $S$. cerevisiae and $S$. paradoxus, but suggests more complex incompatibilities. PLoS Genet 6: e1001038.

Keeling PJ, Roger AJ. 1995. The selfish pursuit of sex. Nature 375: 283.

Keeney S, Giroux CN, Kleckner N. 1997. Meiosis-specific DNA double-strand breaks are catalyzed by Spo11, a member of a widely conserved protein family. Cell $\mathbf{8 8}$ : 375-384.

Kim C, Ye F, Ginsberg MH. 2011. Regulation of integrin activation. Annu Rev Cell Dev Biol 27: 321-345.

Kim H, Wright SJ, Park G, Ouyang S, Krystofova S, Borkovich KA. 2012. Roles for receptors, pheromones, G proteins, and mating type genes during sexual reproduction in Neurospora crassa. Genetics 190: 1389-1404.

Kimchi T, Xu J, Dulac C. 2007. A functional circuit underlying male sexual behaviour in the female mouse brain. Nature 448: 1009-1014.

Klapholz S, Waddell CS, Esposito RE. 1985. The role of the SPO11 gene in meiotic recombination in yeast. Genetics 110: $187-216$.

Kobiyama A, Ikeda Y, Koike K, Ogata T. 2007. Isolation of a differentially expressed gene in separate mating types of the dinoflagellate Alexandrium tamarense. Eur J Phycol 42: $183-190$.

Koerdt A, Godeke J, Berger J, Thormann KM, Albers SV. 2010. Crenarchaeal biofilm formation under extreme conditions. PLoS ONE 5: e14104.

Kondrashov AS. 1988. Deleterious mutations and the evolution of sexual reproduction. Nature 336: 435-440.

Konishi M, Yanagisawa S. 2013. Arabidopsis NIN-like transcription factors have a central role in nitrate signalling. Nat Commun 4: 1617.

Kuroiwa T. 2010. Review of cytological studies on cellular and molecular mechanisms of uniparental (maternal or paternal) inheritance of plastid and mitochondrial genomes induced by active digestion of organelle nuclei (nucleoids). J Plant Res 123: 207-230.

Kuroiwa T, Hori T. 1986. Preferential digestion of male chloroplast nuclei and mitochondrial nuclei during gametogenesis of Bryopsis maxima Okamura. Protoplasma 133: $85-87$.

Lahr DJ, Parfrey LW, Mitchell EA, Katz LA, Lara E. 2011. The chastity of amoebae: Re-evaluating evidence for sex in amoeboid organisms. Proc Biol Sci 278: 2081-2090.

Lee JH, Lin H, Joo S, Goodenough U. 2008a. Early sexual origins of homeoprotein heterodimerization and evolution of the plant KNOX/BELL family. Cell 133: 829-840.

Lee SC, Corradi N, Byrnes EJ 3rd, Torres-Martinez S, Dietrich FS, Keeling PJ, Heitman J. 2008b. Microsporidia evolved from ancestral sexual fungi. Curr Biol 18: $1675-1679$.

Lee SC, Ni M, Li W, Shertz C, Heitman J. 2010. The evolution of sex: A perspective from the fungal kingdom. Microbiol Mol Biol Rev 74: 298-340.

Lin H, Goodenough UW. 2007. Gametogenesis in the Chlamydomonas reinhardtii minus mating type is controlled by two genes, MID and MTD1. Genetics 176: 913-925.

Lin X, Hull CM, Heitman J. 2005. Sexual reproduction between partners of the same mating type in Cryptococcus neoformans. Nature 434: 1017-1021.
Liu Y, Zhang Q, Hu Y, Sodmergen. 2004. Heterogeneous pollen in Chlorophytum comosum, a species with a unique mode of plastid inheritance intermediate between the maternal and biparental modes. Plant Physiol 135: 193-200.

Madhani HD. 2007. From a to $\alpha$ : Yeast as a model for cellular differentiation. Cold Spring Harbor Laboratory Press, Cold Spring Harbor, NY.

Mahlert M, Vogler C, Stelter K, Hause G, Basse CW. 2009. The a2 mating-type-locus gene lga2 of Ustilago maydis interferes with mitochondrial dynamics and fusion, partially in dependence on a Dnm1-like fission component. J Cell Sci 122: 2402-2412.

Malik SB, Pightling AW, Stefaniak LM, Schurko AM, Logsdon JM Jr. 2008. An expanded inventory of conserved meiotic genes provides evidence for sex in Trichomonas vaginalis. PLoS ONE 3: e2879.

Mann RS, Morata G. 2000. The developmental and molecular biology of genes that subdivide the body of Drosophila. Annu Rev Cell Dev Biol 16: 243-271.

Marcon E, Moens PB. 2005. The evolution of meiosis: Recruitment and modification of somatic DNA-repair proteins. BioEssays 27: 795-808.

Mata J, Wilbrey A, Bahler J. 2007. Transcriptional regulatory network for sexual differentiation in fission yeast. Genome Biol 8: R217.

Matagne RF, Beckers M-C. 1983. Perturbation of chloroplast gene transmission in diploid and triploid zygotes of Chlamydomonas reinhardtii by 5-fluorodeoxyuridine. Curr Genet 7: 335-338.

Matsushima R, Hu Y, Toyoda K, Sodmergen, Sakamoto W. 2008. The model plant Medicago truncatula exhibits biparental plastid inheritance. Plant Cell Physiol 49: 81-91.

Maynard Smith J. 1976. A short-term advantage for sex and recombination through sib-competition. J Theor Biol 63: $245-258$.

Metin B, Findley K, Heitman J. 2010. The mating type locus (MAT) and sexual reproduction of Cryptococcus heveanensis: Insights into the evolution of sex and sex-determining chromosomal regions in fungi. PLoS Genet 6: e1000961.

Miller MG, Johnson AD. 2002. White-opaque switching in Candida albicans is controlled by mating-type locus homeodomain proteins and allows efficient mating. Cell 110: 293-302.

Miller MP, Unal E, Brar GA, Amon A. 2012. Meiosis I chromosome segregation is established through regulation of microtubule-kinetochore interactions. eLife 1: e00117.

Mogensen HL. 1996. The hows and whys of cytoplasmic inheritance in seed plants. Am J Bot 83: 383-404.

Moriyama Y, Kawano S. 2010. Maternal inheritance of mitochondria: Multipolarity, multiallelism and hierarchical transmission of mitochondrial DNA in the true slime mold Physarum polycephalum. J Plant Res 123: 139-148.

Motomura T, Nagasato C, Kimura K. 2010. Cytoplasmic inheritance of organelles in brown algae. J Plant Res 123: $185-192$.

Nakamura S. 2010. Paternal inheritance of mitochondria in Chlamydomonas. J Plant Res 123: 163-170.

Narra HP, Ochman H. 2006. Of what use is sex to bacteria? Curr Biol 16: R705-R710. 
Ng WL, Bassler BL. 2009. Bacterial quorum-sensing network architectures. Annu Rev Genet 43: 197-222.

Ni M, Feretzaki M, Sun S, Wang X, Heitman J. 2011. Sex in fungi. Annu Rev Genet 45: 405-430.

Nicklas RB. 1997. How cells get the right chromosomes. Science 275: 632-637.

Nieto-Jacobo F, Pasch D, Basse CW. 2012. The mitochondrial Dnm1-like fission component is required for lga2induced mitophagy but dispensable for starvation-induced mitophagy in Ustilago maydis. Eukaryot Cell 11: 1154-1166.

Nishimura Y, Misumi O, Kato K, Inada N, Higashiyama T, Momoyama Y, Kuroiwa T. 2002. An $\mathrm{mt}^{+}$gamete-specific nuclease that targets $\mathrm{mt}^{-}$chloroplasts during sexual reproduction in C. reinhardtii. Genes Dev 16: 1116-1128.

Nishimura Y, Yoshinari T, Naruse K, Yamada T, Sumi K, Mitani H, Higashiyama T, Kuroiwa T. 2006. Active digestion of sperm mitochondrial DNA in single living sperm revealed by optical tweezers. Proc Natl Acad Sci 103: $1382-1387$.

Nishimura Y, Shikanai T, Nakamura S, Kawai-Yamada M, Uchimiya H. 2012. Gsp1 triggers the sexual developmental program including inheritance of chloroplast DNA and mitochondrial DNA in Chlamydomonas reinhardtii. Plant Cell 24: 2401-2414.

Nowack EC, Grossman AR. 2012. Trafficking of protein into the recently established photosynthetic organelles of Paulinella chromatophora. Proc Natl Acad Sci 109: 53405345.

Nygren K, Strandberg R, Wallberg A, Nabholz B, Gustafsson T, Garcia D, Cano J, Guarro J, Johannesson H. 2011. A comprehensive phylogeny of Neurospora reveals a link between reproductive mode and molecular evolution in fungi. Mol Phylogenet Evol 59: 649-663.

Nygren K, Wallberg A, Samils N, Stajich JE, Townsend JP, Karlsson M, Johannesson H. 2012. Analyses of expressed sequence tags in Neurospora reveal rapid evolution of genes associated with the early stages of sexual reproduction in fungi. BMC Evol Biol 12: 229.

Otto SP, Gerstein AC. 2006. Why have sex? The population genetics of sex and recombination. Biochem Soc Trans 34: 519-522.

Palumbi SR. 2009. Speciation and the evolution of gamete recognition genes: Pattern and process. Heredity 102: $66-$ 76.

Parfrey LW, Lahr DJ, Knoll AH, Katz LA. 2011. Estimating the timing of early eukaryotic diversification with multigene molecular clocks. Proc Natl Acad Sci 108: 1362413629.

Parisi S, McKay MJ, Molnar M, Thompson MA, van der Spek PJ, van Drunen-Schoenmaker E, Kanaar R, Lehmann E, Hoeijmakers JH, Kohli J. 1999. Rec8p, a meiotic recombination and sister chromatid cohesion phosphoprotein of the Rad $21 \mathrm{p}$ family conserved from fission yeast to humans. Mol Cell Biol 19: 3515-3528.

Pauklin S, Burkert JS, Martin J, Osman F, Weller S, Boulton SJ, Whitby MC, Petersen-Mahrt SK. 2009. Alternative induction of meiotic recombination from single-base lesions of DNA deaminases. Genetics 182: 41-54.

Peacock L, Ferris V, Sharma R, Sunter J, Bailey M, Carrington M, Gibson W. 2011. Identification of the meiotic life cycle stage of Trypanosoma brucei in the tsetse fly. Proc Natl Acad Sci 108: 3671-3676.

Perrin N. 2012. What uses are mating types? The "developmental switch" model. Evolution 66: 947-956.

Phadke SS, Zufall RA. 2009. Rapid diversification of mating systems in ciliates. Biol J Linn Soc 98: 187-197.

Phadke SS, Cooper L, Zufall RA. 2012. Is evolution of mating preferences inevitable? Random mating in the multisex system of Tetrahymena thermophila. Int J Evol Biol 2012: 201921.

Pires-daSilva A. 2007. Evolution of the control of sexual identity in nematodes. Semin Cell Dev Biol 18: 362-370.

Pomiankowski A, Nothiger R, Wilkins A. 2004. The evolution of the Drosophila sex-determination pathway. Genetics 166: 1761-1773.

Pontecorvo G. 1956. The parasexual cycle in fungi. Annu Rev Microbiol 10: 393-400.

Poxleitner MK, Carpenter ML, Mancuso JJ, Wang CJ, Dawson SC, Cande WZ. 2008. Evidence for karyogamy and exchange of genetic material in the binucleate intestinal parasite Giardia intestinalis. Science 319: 1530-1533.

Ramesh MA, Malik SB, Logsdon JM Jr. 2005. A phylogenomic inventory of meiotic genes; evidence for sex in Giardia and an early eukaryotic origin of meiosis. Curr Biol 15: 185-191.

Raper JR. 1966. Genetics of sexuality in higher fungi. Ronald, New York.

Reedy JL, Floyd AM, Heitman J. 2009. Mechanistic plasticity of sexual reproduction and meiosis in the Candida pathogenic species complex. Curr Biol 19: 891-899.

Rose MR. 1983. The contagion mechanism for the origin of sex. J Theor Biol 101: 137-146.

Rusche LN, Rine J. 2010. Switching the mechanism of mating type switching: A domesticated transposase supplants a domesticated homing endonuclease. Genes Dev 24: 10 14

Sager R, Granick S. 1954. Nutritional control of sexuality in Chlamydomonas reinhardi. J Gen Physiol 37: 729-742.

Sager R, Tsubo Y. 1961. Genetic analysis of streptomycin resistance and dependence in Chlamydononas. $Z$ Verebungsl 92: 430-438.

Sakakibara K, Ando S, Yip HK, Tamada Y, Hiwatashi Y, Murata T, Deguchi H, Hasebe M, Bowman JL. 2013. KNOX2 genes regulate the haploid-to-diploid morphological transition in land plants. Science 339: 1067-1070.

Salz HK. 2011. Sex determination in insects: A binary decision based on alternative splicing. Curr Opin Genet Dev 21: 395-400.

Sato M, Sato K. 2013. Maternal inheritance of mitochondrial DNA by diverse mechanisms to eliminate paternal mitochondrial DNA. Biochim Biophys Acta 1833: 19791984.

Scannell DR, Byrne KP, Gordon JL, Wong S, Wolfe KH. 2006. Multiple rounds of speciation associated with reciprocal gene loss in polyploid yeasts. Nature 440: 341345 .

Schoustra SE, Debets AJ, Slakhorst M, Hoekstra RF. 2007. Mitotic recombination accelerates adaptation in the fungus Aspergillus nidulans. PLoS Genet 3: e68. 
U. Goodenough and J. Heitman

Schulz B, Banuett F, Dahl M, Schlesinger R, Schafer W, Martin T, Herskowitz I, Kahmann R. 1990. The $b$ alleles of $U$. maydis, whose combinations program pathogenic development, code for polypeptides containing a homeodomain-related motif. Cell 60: 295-306.

Schurko AM, Logsdon JM Jr. 2008. Using a meiosis detection toolkit to investigate ancient asexual "scandals" and the evolution of sex. BioEssays 30: 579-589.

Schurko AM, Neiman M, Logsdon JM Jr. 2009. Signs of sex: What we know and how we know it. Trends Ecol Evol 24: 208-217.

Sekido R, Lovell-Badge R. 2009. Sex determination and SRY: Down to a wink and a nudge? Trends Genet 25: 19-29.

Setohigashi Y, Hamaji T, Hayama M, Matsuzaki R, Nozaki H. 2011. Uniparental inheritance of chloroplast DNA is strict in the isogamous volvocalean Gonium. PLoS ONE 6: e19545.

Sharpley MS, Marciniak C, Eckel-Mahan K, McManus M, Crimi M, Waymire K, Lin CS, Masubuchi S, Friend N, Koike M, et al. 2012. Heteroplasmy of mouse mtDNA is genetically unstable and results in altered behavior and cognition. Cell 151: 333-343.

Sherwood RK, Bennett RJ. 2009. Fungal meiosis and parasexual reproduction-Lessons from pathogenic yeast. Curr Opin Microbiol 12: 599-607.

Singh R, Jagadeeshan S. 2012. Sex and speciation: Drosophila reproductive tract proteins-Twenty five years later. Int J Evol Biol 2012: 191495.

Snell WJ, Goodenough UW. 2008. Flagellar adhesion, flagellar-generated signaling, and gamete fusion during mating. In The Chlamydomonas sourcebook, 2nd ed. Cell Motility and Behavior, Vol. 3 (ed. Witman GB), pp. 369-394. Elsevier, Amsterdam.

Solieri L. 2010. Mitochondrial inheritance in budding yeasts: Towards an integrated understanding. Trends $\mathrm{Mi}$ crobiol 18: 521-530.

Sucgang R, Kuo A, Tian X, Salerno W, Parikh A, Feasley CL, Dalin E, Tu H, Huang E, Barry K, et al. 2011. Comparative genomics of the social amoebae Dictyostelium discoideum and Dictyostelium purpureum. Genome Biol 12: R20.

Takata M, Sasaki MS, Sonoda E, Morrison C, Hashimoto M, Utsumi H, Yamaguchi-Iwai Y, Shinohara A, Takeda S. 1998. Homologous recombination and non-homologous end-joining pathways of DNA double-strand break repair have overlapping roles in the maintenance of chromosomal integrity in vertebrate cells. EMBO J 17: $5497-$ 5508.

Thorne LW, Byers B. 1993. Stage-specific effects of X-irradiation on yeast meiosis. Genetics 134: 29-42.

Toffaletti DL, Nielsen K, Dietrich F, Heitman J, Perfect JR. 2004. Cryptococcus neoformans mitochondrial genomes from serotype $A$ and $D$ strains do not influence virulence. Curr Genet 46: 193-204.

Tzung KW, Williams RM, Scherer S, Federspiel N, Jones T, Hansen N, Bivolarevic V, Huizar L, Komp C, Surzycki R, et al. 2001. Genomic evidence for a complete sexual cycle in Candida albicans. Proc Natl Acad Sci 98: 3249-3253.

Ueno M, Kurokawa R, Renauld H, Watanabe K, Ushimaru T, Uritani M, Yoshinaga K, Hiraoka Y. 2001. Schizosaccharomyces pombe taf $1^{+}$is required for nitrogen starvation- induced sexual development and for entering the dormant GO state. Curr Genet 38: 307-313.

Umen JG. 2011. Evolution of sex and mating loci: An expanded view from Volvocine algae. Curr Opin Microbiol 14: 634-641.

Umen JG. 2013. Genetics: Swinging ciliates' seven sexes. Curr Biol 23: R475-R477.

Umen JG, Goodenough UW. 2001. Control of cell division by a retinoblastoma protein homolog in Chlamydomonas. Genes Dev 15: 1652-1661.

Vanstechelman I, Sabbe K, Vyverman W, Vanormelingen P, Vuylsteke M. 2013. Linkage mapping identifies the sex determining region as a single locus in the Pennate diatom Seminavis robusta. PLoS ONE 8: e60132.

van Werven FJ, Neuert G, Hendrick N, Lardenois A, Buratowski S, van Oudenaarden A, Primig M, Amon A. 2012. Transcription of two long noncoding RNAs mediates mating-type control of gametogenesis in budding yeast. Cell 150: $1170-1181$.

VanWinkle-Swift KP. 1980. A model for the rapid vegetative segregation of multiple chloroplast genomes in Chlamydomonas: Assumptions and predictions of the model. Curr Genet 1: 113-125.

VanWinkle-Swift KP, Burrascano CG. 1983. Complementation and preliminary linkage analysis of zygote maturation mutants of the homothallic alga, Chlamydomonas monoica. Genetics 103: 429-445.

Vlamakis H, Chai Y, Beauregard P, Losick R, Kolter R. 2013. Sticking together: Building a biofilm the Bacillus subtilis way. Nat Rev Microbiol 11: 157-168.

Wagstaff JE, Klapholz S, Waddell CS, Jensen L, Esposito RE. 1985. Meiotic exchange within and between chromosomes requires a common Rec function in Saccharomyces cerevisiae. Mol Cell Biol 5: 3532-3544.

Watanabe Y. 2004. Modifying sister chromatid cohesion for meiosis. J Cell Sci 117: 4017-4023.

Waters PD, Wallis MC, Marshall Graves JA. 2007. Mammalian sex-Origin and evolution of the $\mathrm{Y}$ chromosome and SRY. Semin Cell Dev Biol 18: 389-400.

Wendte JM, Miller MA, Lambourn DM, Magargal SL, Jessup DA, Grigg ME. 2010. Self-mating in the definitive host potentiates clonal outbreaks of the apicomplexan parasites Sarcocystis neurona and Toxoplasma gondii. PLoS Genet 6: e1001261.

West CM. 2003. Comparative analysis of spore coat formation, structure, and function in Dictyostelium. Int Rev Cytol 222: 237-293.

Wilkins AS, Holliday R. 2009. The evolution of meiosis from mitosis. Genetics 181: 3-12.

Wolfe KH, Shields DC. 1997. Molecular evidence for an ancient duplication of the entire yeast genome. Nature 387: 708-713.

Wood AJ, Severson AF, Meyer BJ. 2010. Condensin and cohesin complexity: The expanding repertoire of functions. Nat Rev Genet 11: 391-404.

Wurtz EA, Boynton JE, Gillham NW. 1977. Perturbation of chloroplast DNA amounts and chloroplast gene transmission in Chlamydomonas reinhardtii by 5-fluorodeoxyuridine. Proc Natl Acad Sci 74: 4552-4556.

Xu J, Ali RY, Gregory DA, Amick D, Lambert SE, Yoell HJ, Vilgalys RJ, Mitchell TG. 2000. Uniparental mitochon- 
Origins of Eukaryotic Sexual Reproduction

drial transmission in sexual crosses in Cryptococcus neoformans. Curr Microbiol 40: 269-273.

Yan Z, Xu J. 2003. Mitochondria are inherited from the MATa parent in crosses of the basidiomycete fungus Cryptococcus neoformans. Genetics 163: 1315-1325.

Yan Z, Hull CM, Heitman J, Sun S, Xu J. 2004. SXI1 $\alpha$ controls uniparental mitochondrial inheritance in Cryptococcus neoformans. Curr Biol 14: R743-R744.
Yan Z, Hull CM, Sun S, Heitman J, Xu JP. 2007. The matingtype specific homeodomain genes $S X I 1 \alpha$ and $S X I 2 \mathbf{a}$ coordinately control uniparental mitochondrial inheritance in Cryptococcus neoformans. Curr Genet 51: 187-195.

Zorgo E, Chwialkowska K, Gjuvsland AB, Garre E, Sunnerhagen P, Liti G, Blomberg A, Omholt SW, Warringer J. 2013. Ancient evolutionary trade-offs between yeast ploidy states. PLoS Genet 9: e1003388. 


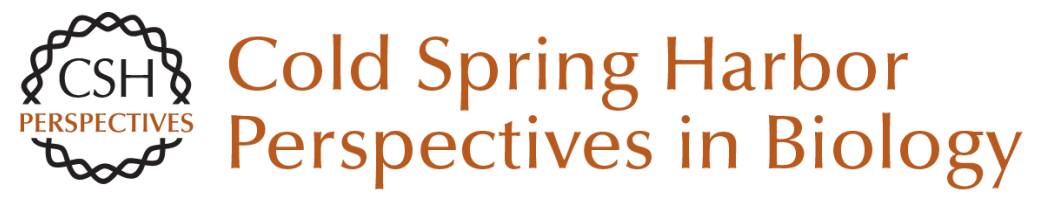

\section{Origins of Eukaryotic Sexual Reproduction}

Ursula Goodenough and Joseph Heitman

Cold Spring Harb Perspect Biol 2014; doi: 10.1101/cshperspect.a016154

Subject Collection The Origin and Evolution of Eukaryotes

The Persistent Contributions of RNA to Eukaryotic Gen(om)e Architecture and Cellular Function Jürgen Brosius

Green Algae and the Origins of Multicellularity in the Plant Kingdom James G. Umen

The Archaeal Legacy of Eukaryotes: A

Phylogenomic Perspective

Lionel Guy, Jimmy H. Saw and Thijs J.G. Ettema

Origin and Evolution of the Self-Organizing Cytoskeleton in the Network of Eukaryotic Organelles Gáspár Jékely

On the Age of Eukaryotes: Evaluating Evidence from Fossils and Molecular Clocks Laura Eme, Susan C. Sharpe, Matthew W. Brown, et al.

Origin of Spliceosomal Introns and Alternative Splicing Manuel Irimia and Scott William Roy

Protein and DNA Modifications: Evolutionary Imprints of Bacterial Biochemical Diversification and Geochemistry on the Provenance of Eukaryotic Epigenetics

L. Aravind, A. Maxwell Burroughs, Dapeng Zhang, et al.
Eukaryotic Origins: How and When Was the Mitochondrion Acquired?

Anthony M. Poole and Simonetta Gribaldo

Bacterial Influences on Animal Origins Rosanna A. Alegado and Nicole King

Missing Pieces of an Ancient Puzzle: Evolution of the Eukaryotic Membrane-Trafficking System Alexander Schlacht, Emily K. Herman, Mary J. Klute, et al.

The Neomuran Revolution and Phagotrophic Origin of Eukaryotes and Cilia in the Light of Intracellular Coevolution and a Revised Tree of Life

Thomas Cavalier-Smith

Protein Targeting and Transport as a Necessary

Consequence of Increased Cellular Complexity Maik S. Sommer and Enrico Schleiff

How Natural a Kind Is "Eukaryote?" W. Ford Doolittle

What Was the Real Contribution of Endosymbionts to the Eukaryotic Nucleus? Insights from Photosynthetic Eukaryotes David Moreira and Philippe Deschamps

For additional articles in this collection, see http://cshperspectives.cshlp.org/cgi/collection/

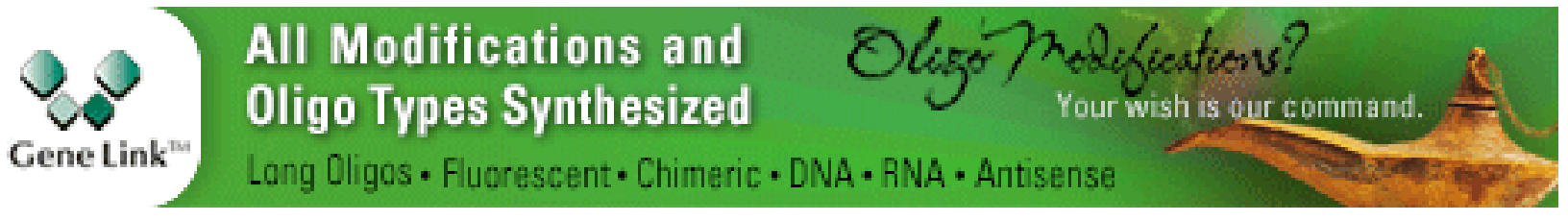


The Eukaryotic Tree of Life from a Global Phylogenomic Perspective Fabien Burki
Bioenergetic Constraints on the Evolution of Complex Life

Nick Lane

For additional articles in this collection, see http://cshperspectives.cshlp.org/cgi/collection/

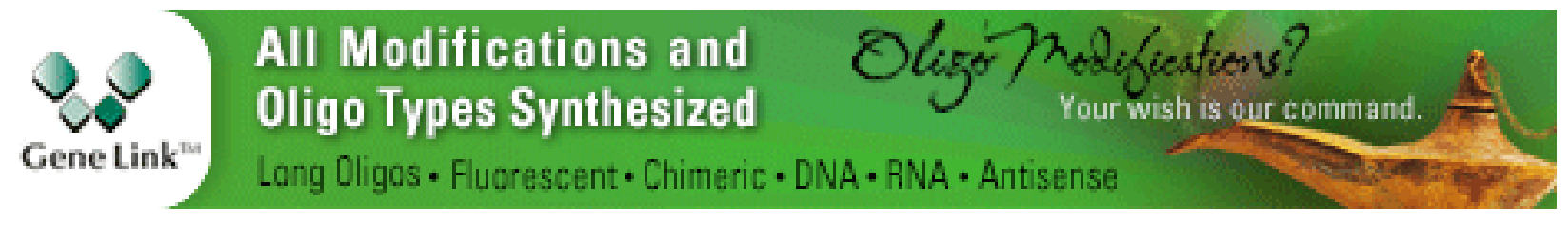

Copyright @ 2014 Cold Spring Harbor Laboratory Press; all rights reserved 